\title{
Nanosilver particles in medical applications: synthesis, performance, and toxicity
}

REVIEW

This article was published in the following Dove Press journal:

International Journal of Nanomedicine

16 May 2014

Number of times this article has been viewed

\section{Liangpeng $\mathrm{Ge}^{1-5, *}$ \\ Qingtao $\mathrm{Li}^{2,3,6, *}$ \\ Meng Wang 2,3 \\ Jun Ouyang6 \\ Xiaojian $\mathrm{Li}^{7}$ \\ Malcolm MQ Xing ${ }^{2,3}$ \\ 'Chongqing Academy of Animal \\ Sciences, Chongqing, People's \\ Republic of China; ${ }^{2}$ Department \\ of Mechanical and Manufacturing \\ Engineering, Department of \\ Biochemistry and Medical Genetics, \\ University of Manitoba, Winnipeg, \\ Canada; ${ }^{3}$ Manitoba Institute of Child \\ Health, Winnipeg, Canada; ${ }^{4}$ Key \\ Laboratory of Pig Industry Sciences, \\ Ministry of Agriculture, Chongqing, \\ People's Republic of China; ${ }^{5}$ Key \\ Laboratory of Pig Industry Sciences, \\ Chongqing, People's Republic of \\ China; ${ }^{6}$ School of Basic Medical \\ Science, Southern Medical University, \\ Guangzhou, People's Republic of \\ China; ${ }^{7}$ Department of Plastic Surgery, \\ Nanfang Hospital, Guangzhou, People's \\ Republic of China}

*These authors contributed equally to this work

Correspondence: Malcolm MQ Xing Department of Mechanical Engineering, 75A Chancellors Circle, University of Manitoba,Winnipeg, MB R3T 5V6, Canada

Tel + I 204480 I396

Fax + I 2042757507

Email xing@cc.umanitoba.ca

Xiaojian Li

Department of Plastic Surgery,

Southern Hospital, Guangzhou,

People's Republic of China, 5I05I5

Tel +86 I37 98I0 3669

Email lixj1999@smu.edu.cn
Abstract: Nanosilver particles (NSPs), are among the most attractive nanomaterials, and have been widely used in a range of biomedical applications, including diagnosis, treatment, drug delivery, medical device coating, and for personal health care. With the increasing application of NSPs in medical contexts, it is becoming necessary for a better understanding of the mechanisms of NSPs' biological interactions and their potential toxicity. In this review, we first introduce the synthesis routes of NSPs, including physical, chemical, and biological or green synthesis. Then the unique physiochemical properties of NSPs, such as antibacterial, antifungal, antiviral, and anti-inflammatory activity, are discussed in detail. Further, some recent applications of NSPs in prevention, diagnosis, and treatment in medical fields are described. Finally, potential toxicology considerations of NSPs, both in vitro and in vivo, are also addressed.

Keywords: nanosilver particles, synthesis, biomedical application, toxicity

\section{Introduction}

Nanosilver particles (NSPs) generally present at 1 to $100 \mathrm{~nm}$ in size in at least one dimension. ${ }^{1-4}$ As particle size decreases, the surface area-to-volume ratio of NSPs increases dramatically, which leads to significant changes in their physical, chemical, and biological properties. NSPs have been among the most commonly used nanomaterials in our health care system for hundreds of years. Recently, NSPs have become of intense interest in biomedical applications (Figure 1), because of their antibacterial, antifungal, antiviral, and anti-inflammatory activity. ${ }^{5,6}$

NSPs have been widely used for diagnosis, ${ }^{7}$ treatment, ${ }^{8}$ drug delivery, ${ }^{9}$ medical device coating, ${ }^{10}$ wound dressings, ${ }^{11}$ medical textiles,,${ }^{12}$ and contraceptive devices. ${ }^{13}$ As the use of nanosilver products is continually increasing, a better understanding of nanosilver biological interactions and their toxicity becomes necessary. This review critically discusses NSP synthesis methods, properties, and current and emerging medical NSP applications. Finally, recent advances concerning NSP potential toxicity will also be described.

\section{NSP synthesis}

Different synthetic NSP routes lead to variable sizes, shapes, morphology, and even stability. Generally, these methods can be classified into three broad categories: physical, chemical, and biological (or green) synthesis.

\section{Physical synthesis}

Evaporation/condensation and laser ablation are the main physical techniques for deriving nanosilver from metal samples. The evaporation/condensation technique uses a furnace 


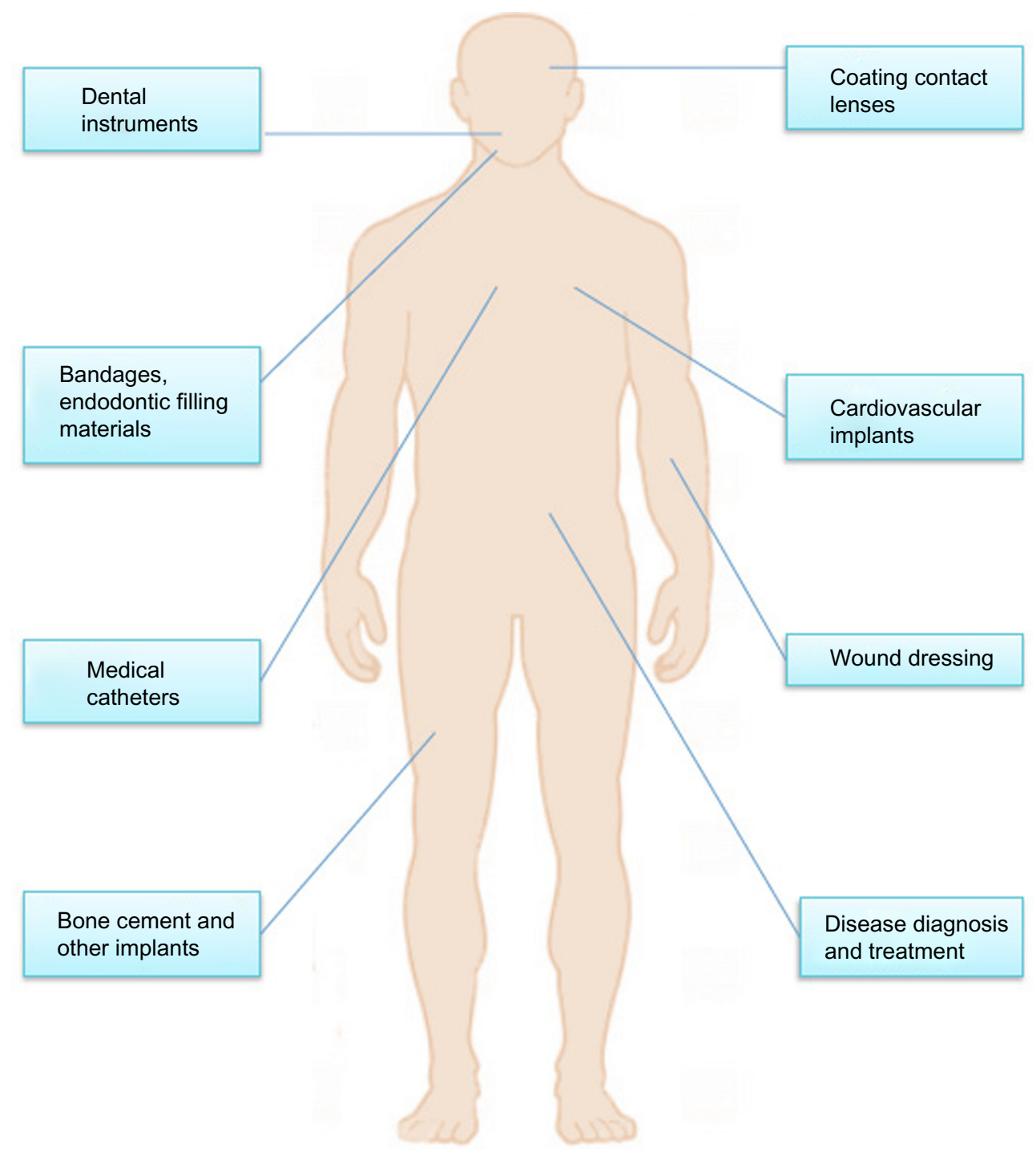

Figure I Biomedical applications of nanosilver particles in human health care.

tube under atmospheric pressure to produce NSPs; however, conventional furnace tubes have several drawbacks, such as high energy consumption, and require a long time to achieve thermal stability. Jung et al used a small ceramic heater with a local heating area, thus the evaporated vapor could cool at a suitable rate and a high concentration of nanosilver could be obtained..$^{14}$ Laser synthesis employs the laser ablation of metals in solution without chemical reagents, which leads to pure nanosilver colloids. ${ }^{15}$ The concentration and morphology of nanosilver are affected by laser fluence and the number of laser shots. Greater laser fluence and amount of time, lead to larger particle size and higher particle concentration. ${ }^{16}$ Recently, Tien et al reported a novel arc-discharge method of producing silver suspension in pure water without any surfactants or stabilizers. ${ }^{17}$ In their research, silver wires were utilized as positive and negative electrodes and etched in pure water.
During discharge, the surface layer of the silver wires was evaporated and condensed in the water, thus stable and welldispersed NSPs of $20-30 \mathrm{~nm}$ in size were obtained. ${ }^{17}$

\section{Chemical synthesis}

Chemical reduction is the most frequent method of nanosilver synthesis, and uses silver salt, reductants, and a stabilizer or capping agents as three main components to control NSP growth (Figure 2). Among these, silver nitrate is a silver salt that is often used for NSPs, due to its low cost and chemical stability compared to the other available silver salts. ${ }^{17}$ The reductants include borohydride, ${ }^{18}$ citrate, ${ }^{19}$ ascorbate, ${ }^{20}$ and hydrogen gas. ${ }^{11}$

Borohydride is a strong reducing agent that can result in small particles with a faster reduction rate, because borohydride can also act as an NSP stabilizer and avoid aggregation 


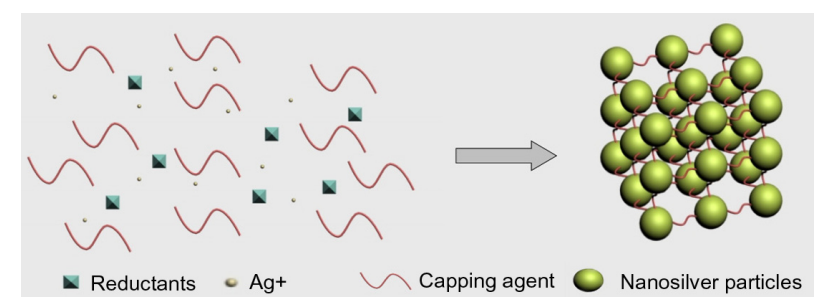

Figure 2 Chemical synthesis of nanosilver particles.

Abbreviation: $\mathrm{Ag}$, silver.

of NSPs during its decomposition. ${ }^{11}$ It is hard to obtain high concentrations of NSPs because of their aggregative instability. Using a stabilizer in preparation is a common strategy. The stabilizers include surfactants and ligands or polymers that contain functional groups such as polyvinylpyrrolidone, poly(ethylene glycol), poly(methacrylic acid), poly(methyl methacrylate), and others. Furthermore, temperature-sensitive polymers such as poly( $\mathrm{N}$-isopropylacrylamide) and collagen can also serve as stabilizers, and nanosilver capped by those chemicals allows for novel thermal switching applications. ${ }^{1}$

NSPs can also be synthesized in a two-phase water-organic system. This method produces uniform and controllable nanoparticles. In this system, metal precursor and reducing agent are separated in two phases, thus the rate of interaction can be controlled by the intensity of interphase transport between aqueous and oil phases; however, large amounts of surfactant and organic solvent may contaminate the surface of formed NSPs, and the removal of surfactant and organic solvent is also time-consuming and expensive.

\section{Biological synthesis}

Biosynthesis (green synthesis) of nanosilver has received extensive attention due to the growing need for environmentally friendly synthesis methods that use eco-friendly reducing and capping agents, such as protein $;{ }^{21}$ peptides $;{ }^{22}$ carbohydrate $;{ }^{23}$ various species of bacteria, ${ }^{24}$ fungi, ${ }^{25}$ and yeast, ${ }^{26}$ and algae and plants. ${ }^{27}$ For example, Naik et al synthesized NSPs of $60-150 \mathrm{~nm}$ in size using silver-binding peptides identified from a combinatorial phage-display peptide library. The peptides were placed in an aqueous solution of $0.1 \mathrm{mM}$ silver nitrate for 24-48 hours at room temperature. ${ }^{21}$ Thomas et al developed an economical, fascicled, and in situ approach to prepare large-scale chitosan-nanosilver (400 nm) films using chitosan as a chelating and stabilizing agent; the films demonstrated excellent antibacterial action against Escherichia coli and Bacillus. ${ }^{28}$ Sintubin et al reviewed different biological synthesis methods using microorganisms or plants for nanosilver synthesis. ${ }^{26}$

In biological synthesis, as the reducing agents and stabilizers are molecules produced by protein, carbohydrate, bacteria, fungi, yeasts, algae, or plants, organic solvents and toxic reagents are avoided. The possible mechanism of biological synthesis includes enzymatic and non-enzymatic reduction (Figure 3). Nicotinamide adenine dinucleotide phosphatedependent reductase can produce NSPs by enzymatic reduction; however, the enzymatic reduction rate is often slow (between 24 and 120 hours). ${ }^{29}$ The non-enzymatic reduction of silver is similar to chemical reduction, but the reducing and stabilizing agents are microorganisms or plants. Nonenzymatic reduction is usually fast, often completed within a few minutes, and can handle extreme parameters, such as high $\mathrm{pH}$ or high temperature, that accelerate the synthesis. ${ }^{24}$

The main advantage of biogenic synthesis over other methods is that the green synthesis avoids organic solvents and toxic reagents. Thus, biosynthesized NSPs are more stable than

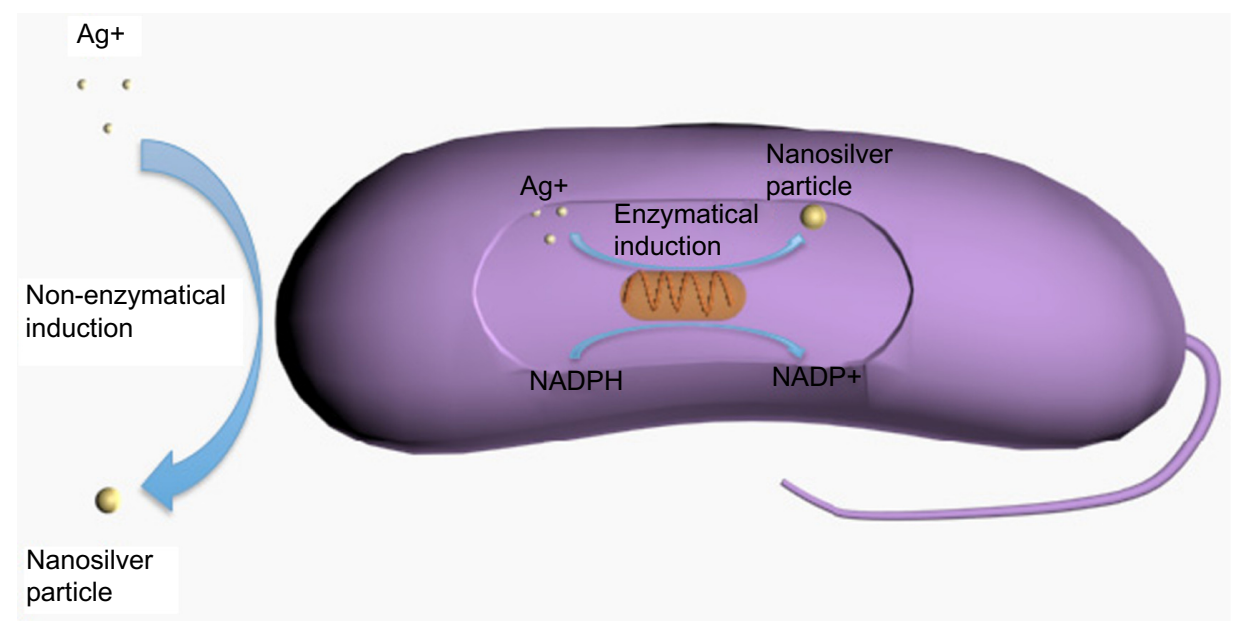

Figure 3 Biological (or green) synthesis of nanosilver particles.

Abbreviations: NADP+, nicotinamide adenine dinucleotide phosphate (oxidized form); NADPH, nicotinamide adenine dinucleotide phosphate (reduced form); Ag, silver. 


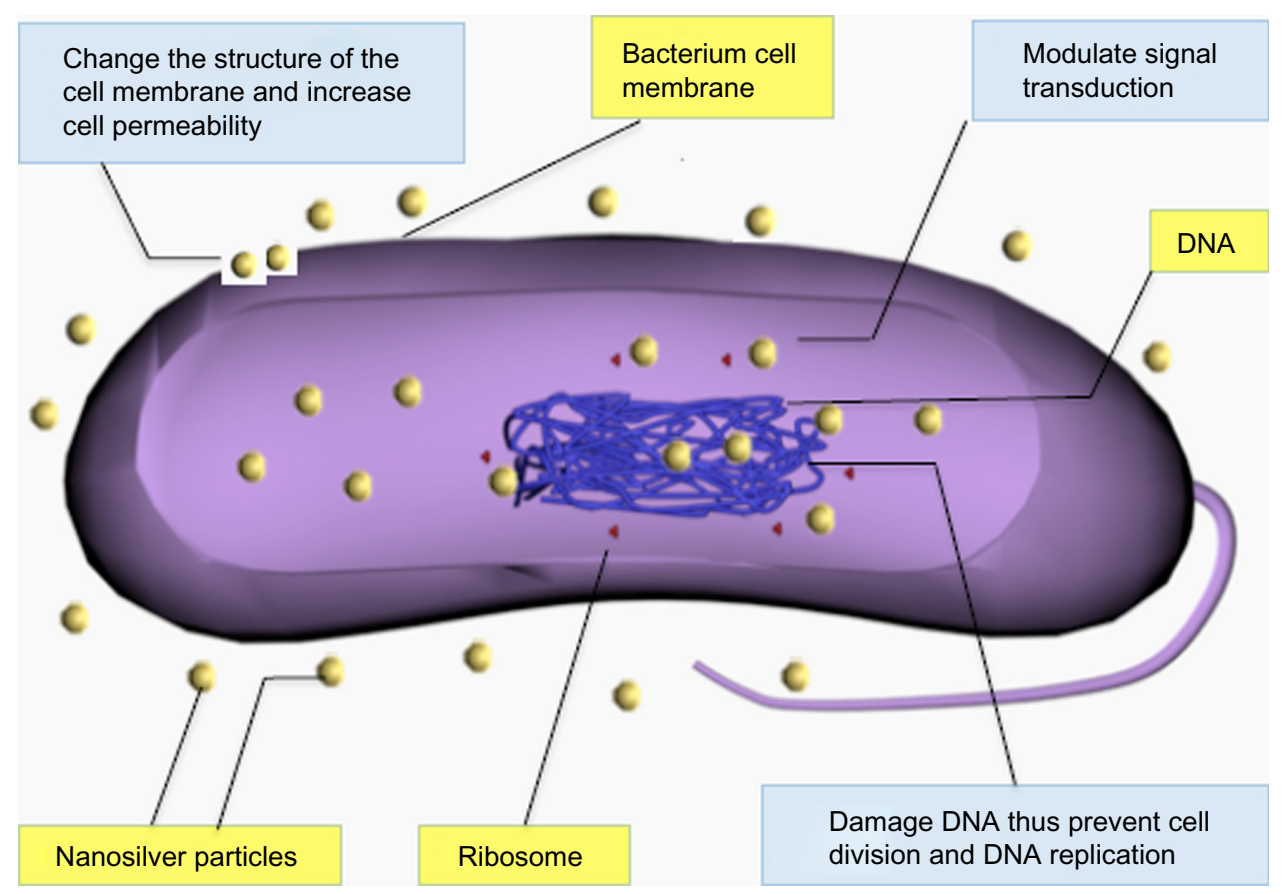

Figure 4 Antibacterial mechanism of nanosilver particles.

Abbreviation: DNA, deoxyribonucleic acid.

those that are chemically produced, and they can remain stable over a long period of time..$^{30}$ In addition, biological synthesis makes it possible to produce NSPs under a nontoxic silver nitrate concentration because microbial cells can continue to multiply, ${ }^{31}$ however, the biosynthesis drawback is that the purification process may lead to pathogenic bacteria and the potential bacteria may cause contamination, which should be a reason for exercising caution in medical application. ${ }^{26}$

\section{NSP performance \\ Antibacterial properties}

NSPs have a broad antibacterial effect on a range of Gramnegative and Gram-positive bacteria and antibiotic-resistant bacteria strains. ${ }^{32}$ Antimicrobial efficacy of NSPs depends on their size and concentration. Normally, a high concentration leads to more effective antimicrobial activity, while particles of small sizes can kill bacteria at a lower concentration. Apart from size and concentration, shape also influences the antimicrobial efficiency of NSPs. Sadeghi et al investigated the antimicrobial activity of different nanosilver shapes, which included silver nanoplates, silver nanorods, and silver nanoparticles, on Staphylococcus aureus and E. coli. They found that silver nanoplates had the best antimicrobial activity. ${ }^{33}$ It has also been reported that NSPs combined with various antibiotics have better antimicrobial effects than NSPs or antibiotics alone. Li et al, for example, found a greater antibacterial effect on
E. coli when amoxicillin and silver nanoparticles were combined than when they were applied separately. ${ }^{34}$

Although the antimicrobial effect of nanosilver has been widely studied, the exact mechanism of NSPs is still elusive. It is widely accepted that NSPs can anchor to and subsequently penetrate the bacterial cell wall, thereby causing structural change of the cell membrane and increasing cell permeability, leading to cell death (Figure 4). ${ }^{35}$ The formation of free radicals and subsequent free radical-induced membrane damage is another potential mechanism, which has been investigated by Kim et al. ${ }^{32}$ It has also been found that NSPs can release silver ions and interact with the thiol groups of many vital enzymes and phosphorus-containing bases, thus inhibiting some functions in cells, such as preventing cell division and DNA replication. ${ }^{36}$ In addition, NSPs may modulate signal transduction through changing the phosphotyrosine profile of bacterial peptides for the potential antibacterial mechanism (Figure 4). ${ }^{37}$

\section{Antifungal properties}

Nanosilver is an effective antifungal agent against a broad spectrum of common fungi. Kim et al investigated NSP antifungal properties on a total of 44 strains of six fungal species, and found that NSPs can inhibit the growth of Candida albicans, Candida glabrata, Candida parapsilosis, Candida krusei, and Trichophyton mentagrophytes effectively. ${ }^{38}$ Nasrollahi et al ${ }^{39}$ and Kim et al ${ }^{40}$ observed that 
NSPs can disrupt cellular membrane and inhibit the normal budding process; however, the exact mechanisms of action of nanosilver against fungi are still not clear.

\section{Antiviral properties}

NSPs are also an antiviral agent against HIV- $1,{ }^{41}$ hepatitis B virus ${ }^{42}$ respiratory syncytial virus, ${ }^{43}$ herpes simplex virus type $1,{ }^{44}$ and monkeypox virus. ${ }^{45}$ It has been observed that NSPs have higher antiviral activity than silver ions, due to species difference as they dissolve to release Ag0 (atomic) and Ag+ (ionic) clusters, whereas silver salts release Ag+ only. ${ }^{46}$ Lara found that the anti-HIV mechanism of nanosilver is based on the inhibition of the initial stages of the HIV-1 cycle. ${ }^{47}$ NSPs can bind to glycoprotein (gp)120, thus inhibit cluster of differentiation (CD) 4-dependent binding, fusion, and infectivity. They act as an effective virucidal agent to block HIV-1 cell-free and cell-associated infection. Furthermore, NSPs inhibit post-entry stages of the HIV-1 life cycle. ${ }^{47}$ Although the mechanism underlying their viral-inhibitory activity is not yet fully understood, NSPs could be considered to be a broad-spectrum agent against a variety of viral strains and are not prone to developing resistance.

\section{Anti-inflammatory properties}

NSPs show anti-inflammatory properties in both animal models and in clinic. For example, in the swine model with contact dermatitis induced by topically applying 1,2-dinitrochlorobenzene, nanosilvers altered the expression of proinflammatory cytokines transforming growth factor- $\beta$ and tumor necrosis factor- $\alpha .^{48}$ Shin and Ye found that NSPs attenuated nasal symptoms in allergic rhinitis mice and inhibited OVA-specific immunoglobulin E, IL-4, and interleukin-10, and that inflammatory cell infiltration and goblet cell hyperplasia were inhibited by nanosilvers. ${ }^{49}$ In a human clinical study, wound dressing containing NSPs promoted the healing of chronic leg ulcers by not only reducing bacteria numbers in the wound bed, but by decreasing inflammatory response as well. ${ }^{8}$ NSPs' ability to reduce cytokine release and matrix metalloproteinases, ${ }^{8,50}$ decrease lymphocyte and mast cell infiltration, ${ }^{48}$ and induce apoptosis in inflammatory cells $\mathrm{s}^{8,49}$ may explain their anti-inflammatory mechanisms.

\section{Medical NSP applications Wound dressings}

Robert Burrell developed the world's first commercially available nanosilver product (Acticoat ${ }^{\mathrm{TM}}$; Smith and Nephew, London, UK) to treat various wounds in clinic, including burns, chronic ulcers, toxic epidermal necrolysis, and pemphigus. ${ }^{51}$ Huang et al observed that NSP-loaded wound dressings significantly reduced the healing time by an average of 3.35 days and increased bacterial clearance from infected wounds compared to silver sulfadiazine, with no adverse effects; ${ }^{52}$ however, Chen et al showed that nanosilver-loaded wound dressings could enhance healing in superficial burn wounds but made no difference in deep burn wounds, compared with $1 \%$ silver sulfadiazine. ${ }^{53}$ This suggests that NSPs accelerate reepithelialization but not angiogenesis.

Currently, new dressings are being fabricated with the aim of increasing antibacterial efficacy and promotion of wound healing. For example, $\mathrm{Lu}$ et al developed a wound dressing composed of NSPs and chitosan, and found that it significantly increased wound healing during treatment of deep partial-thickness wounds and inhibited infection, as well as diminished the risk of silver absorption, compared with $1 \%$ silver sulfadiazine dressings. ${ }^{54}$

\section{Cardiovascular implants}

The first cardiovascular medical device containing silver in clinic was a prosthetic silicone heart valve coated with silver element, which was designed to prevent bacterial infection on the silicone valve and to reduce inflammation response, ${ }^{55}$ however, metal silver may cause hypersensitivity, inhibits normal fibroblast function, and leads to paravalvular leakage in patients. ${ }^{56}$ NSPs are safe and nontoxic in medical devices, unlike metal silver. Therefore, Andara et al synthesized a new nanocomposite with NSPs and diamond-like carbon as a surface coating for heart valves and stents, and found that the surface of the nanocomposite showed antithrombogenic and antibacterial properties..$^{57}$ In addition, Ghanbari et al ${ }^{58}$ and $\mathrm{Fu}$ et $\mathrm{al}^{59}$ also constructed antibacterial multilayer films containing NSPs, and investigated their antibacterial, mechanical, and hemodynamic properties in vitro for use in cardiovascular implant coating.

\section{Catheters}

Much research has been conducted to investigate NSPs as antibacterial materials for coating catheters, including central venous catheters and neurosurgical catheters. Silverline (Spiegelberg GmbH and Co. KG, Hamburg, Germany) and ON-Q Silver Soaker ${ }^{\mathrm{TM}}$ (I-Flow Corporation, CA, USA) are two commercially available medical catheters containing NSPs to prevent catheter-associated infections. ${ }^{51}$ Medical catheters are prone to bacterial infection, which can rapidly spread to the wound and its surrounding, and lead to serious 
complications. Because of their superior antibacterial properties and lack of observed toxicity, NSPs can decrease the incidence of bacterial infection and complications after surgery, thus they have been widely accepted for use in medical catheters. Andara et al found that plastic catheter tubes coated with nanosilver could inhibit bacterium growth in vitro for at least 72 hours, with no significant toxicity, in an animal model. ${ }^{57}$ In a pilot clinical study, 19 patients who received a nanosilver catheter did not show catheter-associated ventriculitis, and all cerebrospinal fluid cultures were negative, while five patients were positive for catheter-associated ventriculitis in the control group (20 patients). ${ }^{60}$

\section{Bone cement}

Alt et al evaluated antibacterial activity of plain poly(methyl methacrylate) bone cement loaded with different NSP concentrations in vitro, and found that bone cement-loaded 1\% nanosilver completely inhibited the proliferation of Staphylococcus epidermidis, methicillin-resistant $S$. epidermidis, and methicillin-resistant S. aureus, with no significant difference between the nanosilver bone cement and the nontoxic control group in quantitative and qualitative cytotoxicity tests. ${ }^{61} \mathrm{NSPs}$ were also added to ultra-high-molecular-weight polyethylene for fabricating inserts for total joint replacement components, and it was found that NSPs drastically reduced the wear and tear of the polymer. ${ }^{62}$

\section{Dental materials}

NSPs also have applications in dental instruments and bandages. Yoshida et al showed that a resin composite incorporated with NSP-containing materials had a long-term inhibitory effect against Streptococcus mutans. ${ }^{63}$ Yamamoto et al also showed that a resin composite containing silver ion-implanted fillers released silver ions with antibacterial effects on oral streptococci. ${ }^{64}$ In addition, Magalhães et al showed that incorporating NSPs in endodontic filling materials provided a significantly enhanced anti-bactericidal effect against Streptococcus milleri, S. aureus, and Enterococcus faecalis. ${ }^{65}$ NSPs in dental adhesives are also very effective against streptococci without affecting the adhesive mechanical properties, thus enabling their use in orthodontic treatments. ${ }^{66}$

\section{Biodiagnosis}

NSPs can be used for bio-diagnosis, where plasmonic properties of NSPs strongly depend on size, shape, and dielectric medium that surrounds it. ${ }^{67}$ Zhou et al developed a silver nanoparticle array biosensor for clinical detection of serum p53 in head and neck squamous cell carcinoma. ${ }^{68}$ NSPs are also employed to produce dual-imaging/therapyimmunotargeted nanoshells to locate cancer cells and can absorb light and selectively destroy targeted cancer cells through photothermal therapy. ${ }^{69}$ In addition, NSPs can detect the interaction between amyloid $\beta$-derived diffusible ligands (ADDL) and the anti-ADDL antibody, which are related to the development of Alzheimer's disease, ${ }^{70}$ however, silver is easily oxidized and forms plasmonically unattractive compounds such as halides in biological solutions, which deteriorates the plasmonic performance of NSPs. ${ }^{18}$

\section{Other medical applications}

NSPs have applications in the diagnosis and treatment of cancer, ${ }^{71}$ and are drug carriers that can deliver therapeutic agents, ${ }^{72}$ which are used in eye care for coating contact lenses. ${ }^{17}$ In addition, the use of nanosilver in combination with vanadium oxide in battery cell components is one example of advanced silver nanotechnology improving battery performance in nextgeneration active implantable medical devices. ${ }^{73}$

\section{NSP toxicity}

NSPs may have potential toxicities at some concentrations and can cause various health problems if used improperly. Thus, it is necessary to address the biosafety of NSPs in human health.

\section{In vitro toxicity}

NSPs have been reported to be cytotoxic to several types of cells, including human peripheral blood mononuclear cells, ${ }^{74}$ human alveolar epithelial cell line (A549) ${ }^{75}$, murine and human alveolar macrophage cell line,${ }^{76}$ neuroendocrine cells, ${ }^{77}$ rat liver cell line, ${ }^{78}$ and mouse germline cells. ${ }^{79}$ Alt et al, however, found that bone cement containing $1.0 \%$ nanosilver did not lead to significant cytotoxicity in mouse fibroblasts (L929) and human osteoblast cell line. ${ }^{61}$ Although the details of the toxic mechanism are unclear, it suggests that NSPs are ionized in the cells, which leads to activate ion channels and changes the permeability of the cell membrane to both potassium and sodium, ${ }^{80}$ interaction with mitochondria, ${ }^{81}$ and induction of the apoptosis pathway via the production of reactive oxygen species, ${ }^{82}$ which leads to cell death.

\section{In vivo toxicity}

Chen and Schluesener have reviewed biodistribution, organ accumulation, degradation, possible adverse effects, and toxicity associated with the medical use of nanosilver. ${ }^{13}$ 
Respiratory tract, gastrointestinal tract, skin, and female genital tract are the main entry portals of nanosilver into the human body through direct substance exchange with the environment. Additionally, systemic administration is also a potential route of entry, since colloidal silver nanoparticles have been exploited for diagnostic imaging or therapeutic purposes. Inhalation and instillation experiments in rats showed that low concentration, but detectable, ultrafine silver $(14.6 \pm 1.0 \mathrm{~nm})$ appeared in the lung and was subsequently distributed to the blood and other organs, such as heart, liver, kidney, and even brain..$^{83}$ In a recent oral toxicity study of rats, Kim et al also found that silver nanoparticles accumulated in blood, liver, lungs, kidneys, stomach, testes, and brain, but NSPs showed no significant genotoxicity after oral administration of silver nanoparticles of $60 \mathrm{~nm}$ average size for 28 days at different doses. ${ }^{84}$ Lee et al showed that NSPs less than $12 \mathrm{~nm}$ in size affected early development of fish embryos, caused chromosomal aberrations and DNA damage, and induced proliferation arrest in cell lines of zebrafish; ${ }^{85}$ however, Lansdown found that silver was not a cause of neurotoxic damage, even though silver deposits have been identified in the region of cutaneous nerves, ${ }^{86}$ and Ji et al found that NSPs did not affect respiratory system in a 28-day in vivo study. ${ }^{87}$

Animal and human studies indicate that it is difficult to remove silver completely once it has been deposited in the body; however, nanosilver can be excreted through the hair, urine, and feces. ${ }^{88}$ There is no consensus on nanosilver's toxicity to humans, and most toxicity investigations of silver nanoparticles are based on in vitro cellular experiments and relatively short-term animal experiments.

\section{Conclusion}

NSPs represent a prominent nanoproduct and are already widely used in medical applications, including wound dressing, diagnosis, and pharmacological treatment. Since the shape, size, and composition of NSPs can have significant effects on their function and possible risks to human health, extensive research is needed to fully understand their synthesis, characterization, and possible toxicity. In this review, we first gave an overview of NSP synthesis, then reviewed applications of NSPs in the field of biomedicine. Finally, possible toxicology was discussed.

There is a limited number of well-controlled studies on the potential toxicities of nanosilver, though these studies tend to suggest that NSPs can induce toxicity in living beings. It should be noted that in vitro conditions are drastically different from in vivo conditions; however, longer-term studies and assessment of NSP toxicity must be conducted so that NSP exposure does not exceed toxic levels.

\section{Acknowledgments}

This work was supported by International Science and Technology Cooperation Program of China (S2013ZR0398), Chongqing Basic Scientific Research Grant (cstc2013jcyjC80001), Chongqing Agriculture Development Grant (14408, 12402), the NSERC Discovery Grant, Manitoba Health Research Council, Dr Moorehouse Fellowship, Manitoba Institute of Child Health and China 863 Project (Grant 2012AA020504).

\section{Disclosure}

The authors report no conflicts of interest in this work.

\section{References}

1. Chen J, Ouyang J, Kong J, Zhong W, Xing MM. Photo-cross-linked and $\mathrm{pH}$-sensitive biodegradable micelles for doxorubicin delivery. ACSAppl Mater Interfaces. 2013;5(8):3108-3117.

2. Mohamed A, Xing MM. Nanomaterials and nanotechnology for skin tissue engineering. Int J Burns Trauma. 2012;2(1):29-41.

3. Tian Y, Chen J, Zahtabi F, Keijzer R, Xing M. Nanomedicine as an innovative therapeutic strategy for pediatric lung diseases. Pediatric Pulmonol. 2013;48(11):1098-1111.

4. Xing M, Zhong W, Xu X, Thomson D. Adhesion force studies of nanofibers and nanoparticles. Langmuir. 2010;26(14):11809-11814.

5. El-Badawy A, Feldhake D, Venkatapathy R. State of the Science Literature Review: Everything Nanosilver and More. Washington, DC: US Environmental Protection Agency; 2010.

6. Zhong W, Xing MM, Maibach HI. Nanofibrous materials for wound care. Cutan Ocul Toxicol. 2010;29(3):143-152.

7. Uchihara T. Silver diagnosis in neuropathology: principles, practice and revised interpretation. Acta Neuropathol. 2007;113(5):483-499.

8. Sibbald RG, Contreras-Ruiz J, Coutts P, Fierheller M, Rothman A, Woo K. Bacteriology, inflammation, and healing: a study of nanocrystalline silver dressings in chronic venous leg ulcers. Adv Skin Wound Care. 2007;20(10):549-558.

9. Skirtach AG, Muñoz Javier A, Kreft O, et al. Laser-induced release of encapsulated materials inside living cells. Angew Chem Int Ed Engl. 2006;45(28):4612-4617.

10. Galiano K, Pleifer C, Engelhardt K, et al. Silver segregation and bacterial growth of intraventricular catheters impregnated with silver nanoparticles in cerebrospinal fluid drainages. Neurol Res. 2008;30(3):285-287.

11. Moore K. A new silver dressing for wounds with delayed healing. Wounds UK. 2006;2(2):70-78.

12. Vigneshwaran N, Kathe AA, Varadarajan PV, Nachane RP, Balasubramanya RH. Functional finishing of cotton fabrics using silver nanoparticles. J Nanosci Nanotechnol. 2007;7(6):1893-1897.

13. Chen X, Schluesener HJ. Nanosilver: a nanoproduct in medical application. Toxicol Lett. 2008;176(1):1-12.

14. Jung JH, Oh HC, Noh HS, Ji JH, Kim SS. Metal nanoparticle generation using a small ceramic heater with a local heating area. J Aerosol Sci. 2006;37(12):1662-1670.

15. Tsuji T, Iryo K, Watanabe N, Tsuji M. Preparation of silver nanoparticles by laser ablation in solution: influence of laser wavelength on particle size. Appl Surf Sci. 2002;202(1-2):80-85.

16. Abid JP, Wark AW, Brevet PF, Girault HH. Preparation of silver nanoparticles in solution from a silver salt by laser irradiation. Chem Commun (Camb). 2002;(7):792-793. 
17. Tien DC, Liao CY, Huang JC, et al. Novel technique for preparing a nano-silver water suspension by the arc-discharge method. Reviews on Advanced Materials Science. 2008;18:750-756.

18. Evanoff DD Jr, Chumanov G. Synthesis and optical properties of silver nanoparticles and arrays. Chemphyschem. 2005;6(7):1221-1231.

19. Pyatenko A, Yamaguchi M, Suzuki M. Synthesis of spherical silver nanoparticles with controllable sizes in aqueous solutions. J Phys Chem C. 2007;111(22):7910-7917.

20. Blanco-Andujar C, Tung LD, Thanh NTK. Synthesis of nanoparticles for biomedical applications. Annual Reports Section "A” (Inorganic Chemistry). 2010;106:553-568.

21. Naik RR, Stringer SJ, Agarwal G, Jones SE, Stone MO. Biomimetic synthesis and patterning of silver nanoparticles. Nat Mater. 2002;1(3): 169-172.

22. Nam KT, Lee YJ, Krauland EM, Kottmann ST, Belcher AM. Peptide-mediated reduction of silver ions on engineered biological scaffolds. ACS Nano. 2008;2(7):1480-1486.

23. Anisha BS, Biswas R, Chennazhi KP, Jayakumar R. Chitosan-hyaluronic $\mathrm{acid} /$ nano silver composite sponges for drug resistant bacteria infected diabetic wounds. Int J Biol Macromol. 2013;62:310-320.

24. Sintubin L, De Windt W, Dick J, et al. Lactic acid bacteria as reducing and capping agent for the fast and efficient production of silver nanoparticles. Appl Microbiol Biotechnol. 2009;84(4): 741-749.

25. Balaji DS, Basavaraja S, Deshpande R, Mahesh DB, Prabhakar BK, Venkataraman A. Extracellular biosynthesis of functionalized silver nanoparticles by strains of Cladosporium cladosporioides fungus. Colloids Surf B Biointerfaces. 2009;68(1):88-92.

26. Sintubin L, Verstraete W, Boon N. Biologically produced nanosilver: current state and future perspectives. Biotechnol Bioeng. 2012;109(10): $2422-2436$

27. Shankar SS, Ahmad A, Sastry M. Geranium leaf assisted biosynthesis of silver nanoparticles. Biotechnol Prog. 2003;19(6):1627-1631.

28. Thomas V, Yallapu MM, Sreedhar B, Bajpai SK. Fabrication, characterization of chitosan/nanosilver film and its potential antibacterial application. J Biomater Sci Polym Ed. 2009;20(14):2129-2144.

29. Anil Kumar S, Abyaneh MK, Gosavi SW, et al. Nitrate reductasemediated synthesis of silver nanoparticles from AgNO3. Biotechnol Lett. 2007;29(3):439-445.

30. Saifuddin N, Wong CW, Yasumira AAN. Rapid biosynthesis of silver nanoparticles using culture supernatant of bacteria with microwave irradiation. E-Journal of Chemistry. 2009;6(1):61-70.

31. Mukherjee P, Ahmad A, Mandal D, et al. Fungus-mediated synthesis of silver nanoparticles and their immobilization in the mycelial matrix: a novel biological approach to nanoparticle synthesis. Nano Lett. 2001;1(10):515-519.

32. Kim JS, Kuk E, Yu KN, et al. Antimicrobial effects of silver nanoparticles. Nanomedicine. 2007;3(1):95-101.

33. Sadeghi B, Garmaroudi FS, Hashemi M, et al. Comparison of the antibacterial activity on the nanosilver shapes: nanoparticles, nanorods and nanoplates. Adv Powder Technol. 2012;23(1):22-26.

34. Li P, Li J, Wu C, Wu Q, Li J. Synergistic antibacterial effects of $\beta$-lactam antibiotic combined with silver nanoparticles. Nanotechnology. 2005;16(9):1912-1917.

35. Sondi I, Salopek-Sondi B. Silver nanoparticles as antimicrobial agent: a case study on E. coli as a model for Gram-negative bacteria. J Colloid Interface Sci. 2004;275(1):177-182.

36. Matsumura Y, Yoshikata K, Kunisaki S, Tsuchido T. Mode of bactericidal action of silver zeolite and its comparison with that of silver nitrate. Appl Environ Microbiol. 2003;69(7):4278-4281.

37. Shrivastava S, Bera T, Roy A, Singh G, Ramachandrarao P, Dash D. Characterization of enhanced antibacterial effects of novel silver nanoparticles. Nanotechnology. 2007;18(22):225103.

38. Kim KJ, Sung WS, Moon SK, Choi JS, Kim JG, Lee DG. Antifungal effect of silver nanoparticles on dermatophytes. J Microbiol Biotechnol. 2008;18(8):1482-1484.
39. Nasrollahi A, Pourshamsian Kh, Mansourkiaee P. Antifungal activity of silver nanoparticles on some of fungi. International Journal of Nano Dimension. 2011;1(3):233-239.

40. Kim KJ, Sung WS, Suh BK, et al. Antifungal activity and mode of action of silver nano-particles on Candida albicans. Biometals. 2009;22(2):235-242.

41. Sun RW, Chen R, Chung NP, Ho CM, Lin CL, Che CM. Silver nanoparticles fabricated in Hepes buffer exhibit cytoprotective activities toward HIV-1 infected cells. Chem Commun (Camb). 2005;(40): 5059-5061.

42. Lu L, Sun RW, Chen R, et al. Silver nanoparticles inhibit hepatitis B virus replication. Antivir Ther. 2008;13(2):253-262.

43. Taylor PL, Omotoso O, Wiskel JB, Mitlin D, Burrell RE. Impact of heat on nanocrystalline silver dressings. Part II: physical properties. Biomaterials. 2005;26(35):7230-7240.

44. Baram-Pinto D, Shukla S, Perkas N, Gedanken A, Sarid R. Inhibition of herpes simplex virus type 1 infection by silver nanoparticles capped with mercaptoethane sulfonate. Bioconjug Chem. 2009;20(8):1497-1502.

45. Rogers JV, Parkinson CV, Choi YW, Speshock JL, Hussain SM. A preliminary assessment of silver nanoparticle inhibition of monkeypox virus plaque formation. Nanoscale Res Lett. 2008;3(4):129-133.

46. Taylor PL, Ussher AL, Burrell RE. Impact of heat on nanocrystalline silver dressings. Part I: chemical and biological properties. Biomaterials. 2005;26(35):7221-7229.

47. Lara HH, Ayala -Nuñez NV, Ixtepan-Turrent L, Rodriguez-Padilla C. Mode of antiviral action of silver nanoparticles against HIV-1. J Nanobiotechnology. 2010;8:1

48. Nadworny PL, Wang J, Tredget EE, Burrell RE. Anti-inflammatory activity of nanocrystalline silver in a porcine contact dermatitis model. Nanomedicine. 2008;4(3):241-251.

49. Shin SH, Ye MK. The effect of nano-silver on allergic rhinitis model in mice. Clin Exp Otorhinolaryngol. 2012;5(4):222-227.

50. Castillo PM, Herrera JL, Fernandez-Montesinos R, et al. Tiopronin monolayer-protected silver nanoparticles modulate IL-6 secretion mediated by Toll-like receptor ligands. Nanomedicine (Lond). 2008;3(5): $627-635$.

51. Chaloupka K, Malam Y, Seifalian AM. Nanosilver as a new generation of nanoproduct in biomedical applications. Trends Biotechnol. 2010;28(11):580-588.

52. Huang Y, Li X, Liao Z, et al. A randomized comparative trial between Acticoat and SD-Ag in the treatment of residual burn wounds, including safety analysis. Burns. 2007;33(2):161-166.

53. Chen J, Han CM, Lin XW, Tang ZJ, Su SJ. [Effect of silver nanoparticle dressing on second degree burn wound]. Zhonghua Wai Ke Za Zhi. 2006;44(1):50-52. Chinese.

54. Lu S, Gao W, Gu HY. Construction, application and biosafety of silver nanocrystalline chitosan wound dressing. Burns. 2008;34(5): 623-628.

55. Grunkemeier GL, Jin RY, Starr A. Prosthetic heart valves: Objective Performance Criteria versus randomized clinical trial. Ann Thorac Surg. 2006;82(3):776-780

56. Jamieson WR, Fradet GJ, Abel JG, et al. Seven-year results with the St Jude Medical Silzone mechanical prosthesis. J Thorac Cardiovasc Surg. 2009;137(5):1109-1115. e2.

57. Andara M, Agarwal A, Scholvin D, et al. Hemocompatibility of diamondlike carbon-metal composite thin films. Diam Relat Mater. 2006;15(11-12):1941-1948.

58. Ghanbari H, Viatge H, Kidane AG, Burriesci G, Tavakoli M, Seifalian AM. Polymeric heart valves: new materials, emerging hopes. Trends Biotechnol. 2009;27(6):359-367.

59. Fu J, Ji J, Fan D, Shen J. Construction of antibacterial multilayer films containing nanosilver via layer-by-layer assembly of heparin and chitosan-silver ions complex. J Biomed Mater Res A. 2006;79(3): 665-674.

60. Lackner P, Beer R, Broessner G, et al. Efficacy of silver nanoparticlesimpregnated external ventricular drain catheters in patients with acute occlusive hydrocephalus. Neurocrit Care. 2008;8(3):360-365. 
61. Alt V, Bechert T, Steinrücke P, et al. An in vitro assessment of the antibacterial properties and cytotoxicity of nanoparticulate silver bone cement. Biomaterials. 2004;25(18):4383-4391.

62. Morley KS, Webb PB, Tokareva NV, et al. Synthesis and characterisation of advanced UHMWPE/silver nanocomposites for biomedical applications. Eur Polym J. 2007;43(2):307-314.

63. Yoshida K, Tanagawa M, Matsumoto S, Yamada T, Atsuta M. Antibacterial activity of resin composites with silver-containing materials. Eur J Oral Sci. 1999;107(4):290-296.

64. Yamamoto K, Ohashi S, Aono M, Kokubo T, Yamada I, Yamauchi J. Antibacterial activity of silver ions implanted in $\mathrm{SiO} 2$ filler on oral streptococci. Dent Mater. 1996;12(4):227-229.

65. Magalhães APR, Santos LB, Lopes LG, et al. Nanosilver application in dental cements. ISRN Nanotechnology. 2012;2012:1-6.

66. Ahn SJ, Lee SJ, Kook JK, Lim BS. Experimental antimicrobial orthodontic adhesives using nanofillers and silver nanoparticles. Dent Mater. 2009;25(2):206-213.

67. Haes AJ, Van Duyne RP. A nanoscale optical blosensor: sensitivity and selectivity of an approach based on the localized surface plasmon resonance spectroscopy of triangular silver nanoparticles. J Am Chem Soc. 2002;124(35):10596-10604.

68. Zhou W, Ma Y, Yang H, Ding Y, Luo X. A label-free biosensor based on silver nanoparticles array for clinical detection of serum p53 in head and neck squamous cell carcinoma. Int J Nanomedicine. 2011;6:381-386.

69. Loo C, Lowery A, Halas N, West J, Drezek R. Immunotargeted nanoshells for integrated cancer imaging and therapy. Nano Lett. 2005;5(4):709-711.

70. Haes AJ, Hall WP, Chang L, Klein WL, Van Duyne RP. A localized surface plasmon resonance biosensor: first steps toward an assay for Alzheimer's disease. Nano Lett. 2004;4(6):1029-1034.

71. Liu J, Zhao Y, Guo Q, et al. TAT-modified nanosilver for combating multidrug-resistant cancer. Biomaterials. 2012;33(26):6155-6161.

72. Skirtach AG, Antipov AA, Shchukin DG, Sukhorukov GB. Remote activation of capsules containing Ag nanoparticles and IR dye by laser light. Langmuir. 2004;20(17):6988-6992.

73. Etheridge ML, Campbell SA, Erdman AG, Haynes CL, Wolf SM, McCullough J. The big picture on nanomedicine: the state of investigational and approved nanomedicine products. Nanomedicine. 2013;9(1):1-14.

74. Shin SH, Ye MK, Kim HS, Kang HS. The effects of nano-silver on the proliferation and cytokine expression by peripheral blood mononuclear cells. Int Immunopharmacol. 2007;7(13):1813-1818.
75. Park S, Lee YK, Jung M, et al. Cellular toxicity of various inhalable metal nanoparticles on human alveolar epithelial cells. Inhal Toxicol. 2007;19 Suppl 1:59-65.

76. Soto K, Garza KM, Murr LE. Cytotoxic effects of aggregated nanomaterials. Acta Biomater. 2007;3(3):351-358.

77. Hussain SM, Javorina AK, Schrand AM, Duhart HM, Ali SF, Schlager JJ. The interaction of manganese nanoparticles with PC-12 cells induces dopamine depletion. Toxicol Sci. 2006;92(2): 456-463.

78. Hussain SM, Hess KL, Gearhart JM, Geiss KT, Schlager JJ. In vitro toxicity of nanoparticles in BRL 3A rat liver cells. Toxicol In Vitro. 2005;19(7):975-983.

79. McAuliffe ME, Perry MJ. Are nanoparticles potential male reproductive toxicants? A literature review. Nanotoxicology. 2007;1(3): 204-210.

80. Kone BC, Kaleta M, Gullans SR. Silver ion (Ag+)-induced increases in cell membrane $\mathrm{K}+$ and $\mathrm{Na}+$ permeability in the renal proximal tubule: reversal by thiol reagents. J Membr Biol. 1988;102(1):11-19.

81. Carlson C, Hussain SM, Schrand AM, et al. Unique cellular interaction of silver nanoparticles: size-dependent generation of reactive oxygen species. J Phys Chem B. 2008;112(43):13608-13619.

82. Hsin YH, Chen CF, Huang S, Shih TS, Lai PS, Chueh PJ. The apoptotic effect of nanosilver is mediated by a ROS- and JNK-dependent mechanism involving the mitochondrial pathway in NIH3T3 cells. Toxicol Lett. 2008;179(3):130-139.

83. Takenaka S, Karg E, Roth C, et al. Pulmonary and systemic distribution of inhaled ultrafine silver particles in rats. Environ Health Perspect. 2001;109 Suppl 4:547-551.

84. Kim YS, Kim JS, Cho HS, et al. Twenty-eight-day oral toxicity, genotoxicity, and gender-related tissue distribution of silver nanoparticles in Sprague-Dawley rats. Inhal Toxicol. 2008;20(6):575-583.

85. Lee KJ, Nallathamby PD, Browning LM, Osgood CJ, Xu XH. In vivo imaging of transport and biocompatibility of single silver nanoparticles in early development of zebrafish embryos. ACS Nano. 2007;1(2):133-143.

86. Lansdown AB. Critical observations on the neurotoxicity of silver. Crit Rev Toxicol. 2007;37(3):237-250.

87. Ji JH, Jung JH, Kim SS, et al. Twenty-eight-day inhalation toxicity study of silver nanoparticles in Sprague-Dawley rats. Inhal Toxicol. 2007;19(10):857-871.

88. DiVincenzo GD, Giordano CJ, Schriever LS. Biologic monitoring of workers exposed to silver. Int Arch Occup Environ Health. 1985;56(3):207-215.
International Journal of Nanomedicine

\section{Publish your work in this journal}

The International Journal of Nanomedicine is an international, peerreviewed journal focusing on the application of nanotechnology in diagnostics, therapeutics, and drug delivery systems throughout the biomedical field. This journal is indexed on PubMed Central, MedLine, CAS, SciSearch $\AA$, Current Contents ${ }^{\circledR} /$ Clinical Medicine,

\section{Dovepress}

Journal Citation Reports/Science Edition, EMBase, Scopus and the Elsevier Bibliographic databases. The manuscript management system is completely online and includes a very quick and fair peer-review system, which is all easy to use. Visit http://www.dovepress.com/ testimonials.php to read real quotes from published authors. 